\title{
Global urban subway development, construction material stocks, and embodied carbon emissions
}

\author{
Ruichang Mao ${ }^{1}$, Yi Bao $^{2}$, Huabo Duan (iD ${ }^{3} \&$ Gang Liu (i) ${ }^{1 凶}$
}

Urban subway system, as an important type of urban transportation infrastructure, can provide mass mobility service and help address urban sustainability challenges such as traffic congestion and air pollution. The continuous construction of subways, however, causes large amounts of construction materials and embodied greenhouse gas (GHG) emissions. In this study, we characterized the patterns of subway development, construction material stocks, and embodied emissions covering all 219 cities in the world in which subways are found by July 2020. The global subway length reached $16,419 \mathrm{~km}$ in 2020 , and the construction material stocks amounted to 2.5 gigatons, equaling to an embodied emission of 560 megatons. In particular, China's subway system contributes to $40 \%$ of the total global stocks, with a pattern of moderate and steady stocks growth before 2010 and a rapid expansion afterwards, implying the late-development advantages and infrastructure-based urbanization mode. Our results demonstrated that identifying the spatiotemporal characteristics of subway materials stocks development is imperative for benchmarking future resource demand, informing sustainable subway planning, prospecting urban mining and waste management opportunities and challenges, and mitigating the associated environmental impacts for global GHG emission reduction.

\footnotetext{
${ }^{1}$ SDU Life Cycle Engineering, Department of Green Technology, University of Southern Denmark, Odense, Denmark. ${ }^{2}$ Institute of Remote Sensing and Geographical Information Systems and Beijing Key Lab of Spatial Information Integration \& Its Applications, Peking University, Beijing, China. ${ }^{3}$ College of Civil Engineering, Shenzhen University, Shenzhen, China. ${ }^{{ }}$email: gli@igt.sdu.dk
} 


\section{Introduction}

ransportation infrastructures provide connectivity and mobility services to modern societies. They are essential for ensuring human development and addressing sustainability challenges (Wann-Ming, 2019; Thacker et al., 2019). As a widely acknowledged planning concept for maximizing space use, the transit-oriented development has boosted public transport development, promoted sustainable and low-carbon urban growth, and accelerated transportation networks in the past decades (Renne, 2016; Nasri and Zhang, 2014). Nowadays, transportation networks have already occupied over $25 \%$ of the global urban built-up area (May, 2013).

The subway system, in particular, is one of the most sought urban transportation infrastructures in addressing urban traffic congestion (Yang et al., 2018) and air quality issues (Li et al., 2019). Subways were constructed and operated firstly in Europe (1863 in London) and North America (1892 in Chicago) in the late nineteenth century. Since then, it has developed rapidly worldwide, especially for cities in developing countries such as China and India in the past decade (UITP, 2018). However, the continuous subway construction caused significant construction materials demand and greenhouse gas (GHG) emissions throughout the entire lifespan (Müller et al., 2013; Lanau et al., 2019). Furthermore, due to the long lifetime of subways and for safety and/or heritage reasons, only a small share of the subway built-in materials are potentially available as secondary resources (e.g., 3\% for Vienna's subway network within 100 years) (Lederer et al., 2016a), leading to both challenges and opportunities for urban mining and waste management at the end of subway service life. Therefore, understanding the development patterns and accumulated material stocks of subways is essential to estimate future resource demand, waste generation, recycling potentials, and identify effective environmental mitigation strategies for sustainable urban subway planning and management.

Most studies on subway development in the transportation literature focused on evaluating its effectiveness in commuting behaviors (Wu and Hong, 2017), reducing traffic congestion (Prud'homme et al., 2012), and improving air quality (Chenyihsu and Whalley, 2012), while the resource and waste perspectives are not often investigated. The past years have seen several studies on characterizing the quantity, quality, and composition of urban infrastructure stocks such as roads (Nguyen et al., 2019), highways (Guo et al., 2017), railways (Wang et al., 2016), and water pipes (Pauliuk et al., 2014). However, only a few of these studies have specifically addressed subway system for a handful case cities, e.g., Vienna (Lederer et al., 2016b; Gassner et al., 2020), Toronto (Saxe et al., 2017), Beijing (Mao et al., 2020), and Shanghai (Han et al., 2018). Furthermore, a few knowledge gaps remain unaddressed in these case studies on subway stocks:

- They often cover only subway tunnels in the material composition indicators (MCIs) used for stock calculation (Han et al., 2018), and neglect other large parts such as subway stations, entrances and exits, and ventilation systems, which present extensive materials as well.

- The subway stock results are often derived from statistics in aggregated values (Gassner et al., 2020; Saxe et al., 2017), thus the spatial patterns and material stocks distribution are not analyzed, which would be essential for practical urban mining and waste management (e.g., for spatial planning and optimization of waste supply and demand).

- Previous studies often address individual cities, so cannot benchmark subway material stocks results across cities and reveal spatiotemporal variations and growth patterns in the long run. For example, the subway material stocks contributed to $13.9 \%$ of materials in Vienna's transport sector (Gassner et al., 2020), while only accounted for $2.6 \%$ and $0.5 \%$ in the urban built-environment stocks of Beijing (Mao et al., 2020) and Shanghai (Han et al., 2018), respectively. Moreover, the quantity, composition, location, and embodied GHG emissions of the global subway material stocks are hitherto poorly understood at the global level.

In this paper, we aim to address the above-mentioned gaps by identifying the historical subway patterns and estimating the global subway construction material stocks up to 2020. Owing to data availability and as a large country that is experiencing an unprecedented urbanization process and an upgrading infrastructure investment (Zhou et al., 2019), China was further selected as a case to explore the spatiotemporal characteristics of subway material stocks development. Specifically, several questions are emphasized in the research: (1) What are the historical development patterns of the subway system over 150 years of history? (2) What are the quantity, composition, growth, distribution, and associated environmental impacts of global subway material stocks? (3) What is China's subway system's role in a global context, and what are the spatiotemporal characteristics of subway material stocks in China? (4) Based on the identified features, what are the sustainable policy implications for future stock development in subway systems?

\section{Methods}

City selection and data source. Based on exhaustive data collection, we have included all the 219 cities in the world in which subways are found by July 2020 in this research. These cities are further grouped into seven regions: 37 cities in China (mainland China only, excluding Hong Kong, Macau, and Taiwan), 58 in other Asia (Asian cities except for mainland China), 76 in Europe, 23 in North America, 22 in Latin America, 2 in Africa, and 1 in Oceania. The list is presented in the Supplementary Information Table S1 to S7.

For Chinese cities, subway-related information on operation time, length of tunnels, number of stations, number of lines, number of entrances and exits, and ventilation systems were collected from official websites of respective metro corporations (e.g., Beijing Mass Transit Railway Operation Corporation Limited for the case of Beijing) (Beijing Mass Transit Railway Operation Corporation Limited, 2020), as detailed in Table S8 to S44 in the Supplementary Information. Socioeconomic data including the population and the urban built-up area were obtained from their respective Statistical Yearbooks (e.g., Beijing Statistical Yearbook 2019 for the case of Beijing) (Beijing Municipal Bureau of Statistics, 2020) (detailed in Table S45 in the Supplementary Information). The geolocalized data of subway infrastructures, including polyline data for tunnels and polygon data for stations were retrieved from AutoNavi Company (AutoNavi Company, 2020).

For the other 182 world cities except those in China mainland, we referred to World Metro Database (Serradell and Kennes, 2017) for subway network length, the number of subway stations, and opening year. Gross Domestic Product (GDP) data of 153 cities (including the 37 Chinese cities) for the year 2014 are collected from Global Metro Monitor database (Brookings Institute, 2018), which were adjusted by a purchasing power parity (PPP) conversion factor. Population in 2018 and built-up area data are collected from respective national statistics (e.g., the U.S. Census Bureau for the U.S. cities) (U.S. Census Bureau, 2020). See details in Table S46 to S51 in the Supplementary Information. 
In addition, we have compiled annual ridership data of subways for a total of 25 cities with the busiest and longest subway systems from respective official reports (e.g., data for New York from Metropolitan Transportation Authority of New York City Transit) (Metropolitan Transportation Authority (MTA), 2019). The population densities of these 25 cities were retrieved from the London Datastore database (Greater London Authority (GLA), 2014) (see details in Table S52 in the Supplementary Information). The historical population and GDP data since 2000 of five selected Chinese cities with the longest subway history (Beijing, Shanghai, Guangzhou, Shenzhen, and Chengdu) were obtained from respective Statistical Yearbooks (e.g., Shanghai Statistical Yearbook 2019 for the case of Shanghai) (Shanghai Municipal Bureau of Statistics, 2020) (detailed in Table S53 and S54 in the Supplementary Information).

Compiling subway material composition indicators. For Chinese cities, we compiled the MCIs from construction bill of quantities provided by construction companies and archives in three cities for data around 2015, i.e., Shenzhen (South China), Wuhan (Central China), and Shenyang (North China) (see a snapshot of subway bill of quantities in Fig. S1 in the Supplementary Information). Over 300 material use processes are found in each subway construction project. These material consumptions are further aggregated into five large components: subway tunnel, station, ancillary road (pavement construction around the station), entrance and exit, and ventilation system. We used the mean values from material inventories of the three case cities for MCIs of the subway tunnel, entrance and exit, ventilation system, and the weighted average for the material composition in stations and ancillary roads between transfer and normal stations due to large material composition variance. In the end, 11 construction materials are presented as they constitute over $99 \%$ of the total consumption (Table 1).

For global cities, we compared the subway MCIs in China with the available literature MCIs data of six subway lines in Vienna (Lederer et al., 2016a) and one line in Toronto (Saxe et al., 2017), and simplified the non-Chinese subway MCIs in two components (i.e., subway tunnel and station) and five material types (i.e., cement, gravel, sand, steel and copper). We then further used the minimum and maximum values of the MCIs for uncertainty analysis (See Table S55 in the Supplementary Information).

Subway material stocks calculation. Based on the subway specific data (e.g., tunnel length and number of stations, detailed in the Supplementary Information) and MCIs data compiled (see in Table 1 and Table S55), a bottom-up stock accounting approach is adopted for estimating subway material stocks (by five components for Chinese cities and by two components for nonChinese cities). As shown in Equation 1, the construction materials used in the subway system were calculated based on the length of subway tunnels, the number of subway stations, entrances and exits, ventilation systems, and their corresponding MCIs.

$$
\begin{gathered}
\operatorname{MS}_{m}(t)=\sum_{m} L_{\mathrm{st}}(t) \times \mathrm{MCI}_{\mathrm{st}, m}+N_{s}(t) \times\left(\mathrm{MCI}_{s, m}+\mathrm{MCI}_{a, m}\right) \\
+N_{e}(t) \times \mathrm{MCI}_{e, m}+N_{v}(t) \times \mathrm{MCI}_{v, m}
\end{gathered}
$$

where $\mathrm{MS}_{m}(t)$ is the subway stock of material $m$ in year $t ; L_{\mathrm{st}}(t)$ refers to the length of subway tunnel constructed in year $t ; N_{s}(t)$, $N_{e}(t)$, and $N_{v}(t)$ are the number of subway station, entrance and exit, and ventilation system, respectively; and $\mathrm{MCI}_{\mathrm{st}, m}, \mathrm{MCI}_{s, m}$, $\mathrm{MCI}_{a, m}, \mathrm{MCI}_{e, m}$, and $\mathrm{MCI}_{v, m}$ are the composition indicator of material $m$ in one kilometer subway tunnel, and in one unit subway station, ancillary road, entrance and exit, and ventilation system, respectively.

Spatial analysis of subway material stocks in China. Owing to data availability and as the country with the world's largest subway material stocks, we have chosen China for further spatial analysis of its subway material stocks across cities. Polyline data of subway tunnels and polygon data of subway stations are geographically transformed to raster data in a resolution of $500 \times$ $500 \mathrm{~m}$ in QGIS software (QGIS, 2018). In total, 15,858 grids across the 37 Chinese cities with stock data are plotted to identify the spatial stock distributions and the above- and underground characteristics. By integrating the gridded population data (acquired from WorldPop dataset) (WorldPop Mainland China dataset, 2020), the correlations between subway stocks and population densities are revealed for more in-depth implications.

Embodied emissions estimation. The embodied emissions of subway materials stocks, implying the environmental impacts of subway construction materials in production and manufacturing phases, are calculated based on the estimated subway stocks and corresponding GHG emission factors. The GHG emission factors, which represent cradle-to-gate requirements for raw material extraction, manufacture, and processing, are taken from a Life Cycle Database in eBalance software (CLCD Database, 2015) for estimating the embodied emissions in subway material stocks (see the GHG emission factors of selected materials in Table S56 in the Supplementary Information). Equation 2 illustrates the quantification of embodied GHG emissions (measured in $\mathrm{CO}_{2}$

\begin{tabular}{|c|c|c|c|c|c|}
\hline Material & Tunnel $(t / \mathbf{k m})$ & Station (t/unit) & Ancillary road ( $t /$ unit) & Entrance and exit ( $t /$ unit) & Ventilation system ( $t /$ unit) \\
\hline Asphalt & / & 9.4 & 3021.0 & 0.7 & 1.0 \\
\hline Cement & 1440.2 & 9233.9 & 1250.7 & 637.2 & 814.8 \\
\hline Copper & / & 4.5 & / & / & / \\
\hline Fly ash & 593.0 & 3802.2 & 515.0 & 262.4 & 335.5 \\
\hline Geotextile & 0.04 & / & 1.3 & / & / \\
\hline Gravel & 8471.9 & $54,317.3$ & 8035.9 & 3748.2 & 4793.2 \\
\hline Silica fume & 677.8 & 4345.4 & 588.6 & 299.9 & 383.5 \\
\hline Mortar & / & 2612.4 & / & 37.8 & 397.6 \\
\hline Sand & 7201.1 & $46,169.7$ & 6253.5 & 3186.0 & 4074.2 \\
\hline Steel & 1144.6 & 9121.6 & / & 690.6 & 1042.2 \\
\hline Waterproof & 0.5 & 8.5 & / & 10.0 & 12.2 \\
\hline Total & 19,529 & 129,625 & 19666 & 8873 & 11,854 \\
\hline
\end{tabular}

Table 1 Subway material composition indicators (MCls) of Chinese cities. 

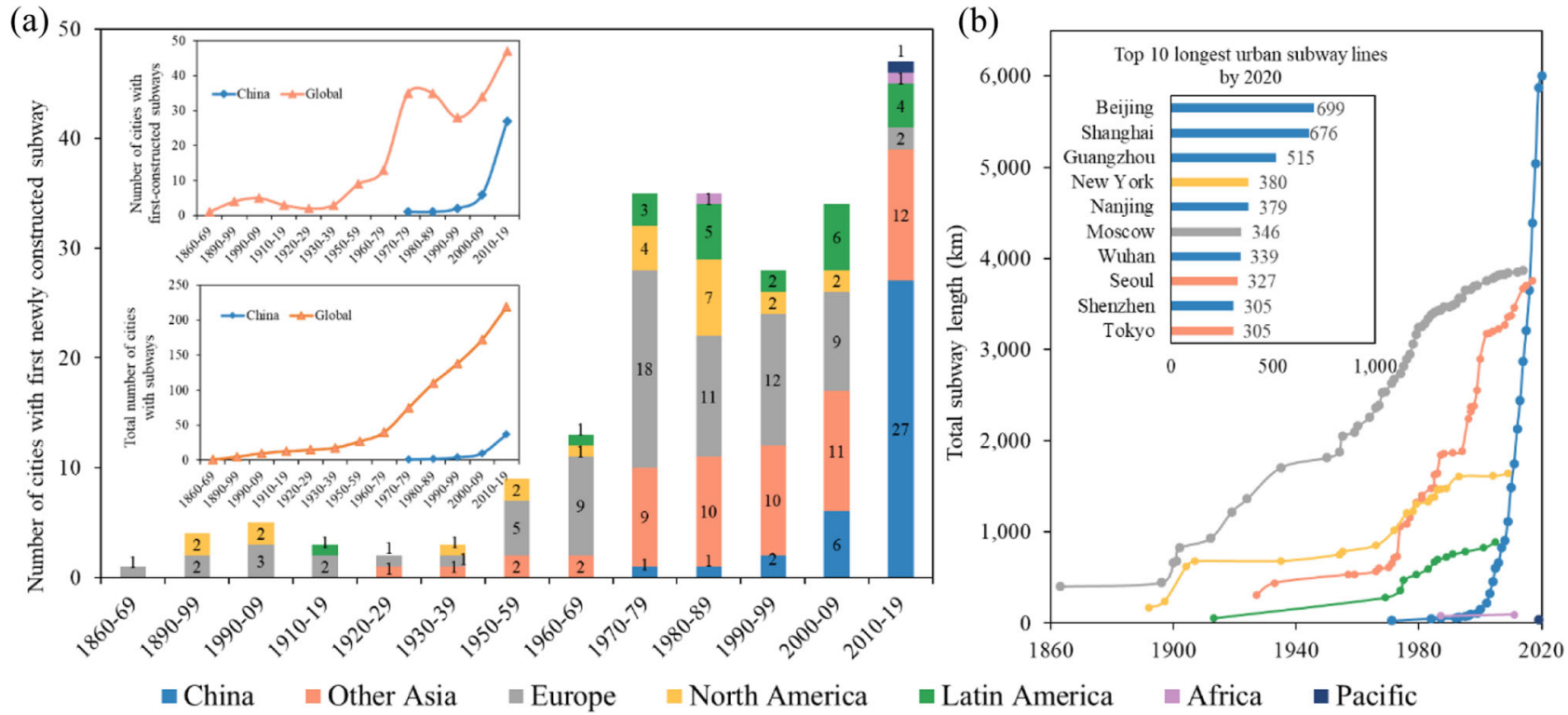

Fig. 1 The temporal dynamics of the number of cities with subway system and the total length of suways. (a) The decadal increase of cities with subway system per world region; (b) The increase of total subway length per world region and the ten longest urban subway systems by July 2020 . Note: No subway systems were built in the time period of 1870 to 1889 and 1940 to 1949 .

equivalent, $\left.\mathrm{CO}_{2} \mathrm{e}\right)$ in the subway system.

$$
\mathrm{EC}_{m, i}=\sum_{m, i}\left(\mathrm{EF}_{m} \times \mathrm{MS}_{m, i}\right)
$$

where $\mathrm{EC}_{m, i}$ is the total embodied GHG emissions of material $m$ in component $i ; \mathrm{EF}_{i}$ represents the emission factor of material $m$; and $\mathrm{MS}_{m, i}$ refers to the material stocks of type $m$ in component $i$.

Uncertainty analysis. Our model results depend on the complied subway MCIs and the collected subway physical size. The main sources of uncertainty include the temporal variations of Chinese subway MCIs from 1971 to 2020 and the estimation of nonChinese subway MCIs across global cities. The former is mainly due to construction technologies improvement, and thus we assess the MCIs variation of Chinese subways between 1971 to 2020 as a normal distribution, with the deviation of uncertainties ranging from $0 \%$ (in 2015) to $20 \%$ (in 1971). For the latter, we assumed the non-Chinese subway MCIs as a triangular distribution, by simplifying the MCIs in two components and five material types with assumed minimum and maximum values. Monte Carlo simulation in Crystal Ball software was employed with $95 \%$ confidence intervals (CIs) and 100,000 trials to estimate uncertainties in the results of subway material stocks.

\section{Results and discussion}

Global urban subway development patterns. Figure 1 shows the growth patterns of urban subway networks across the seven defined world regions from 1860 to 2020. Since the first subway line started operation in 1863 in London, the number of cities with subway systems has increased gradually. The increase appears particularly rapid since the 1970s when the oil crises boosted social and governmental interests in public transportation (Faivre d'Arcier, 2014). While European and other Asian cities dominated such an increase in the past one and half centuries, China experienced a surge since 2010, contributing more than half of the global number of cities with first-constructed subways. North American cities developed comparably slowly in the past decades, due assumingly to its impactful automobile industry and path dependence on automobile use (Kennedy, 2002).
As of 1 July 2020, subway networks are found in 219 cities with a total length of $16419 \mathrm{~km}$. China alone constitutes $36.6 \%$ $(6005 \mathrm{~km})$, followed by Europe $(3866 \mathrm{~km}, 23.5 \%)$, other Asia $(3756 \mathrm{~km} 22.9 \%)$, North America $(1644 \mathrm{~km}, 10.0 \%)$, and Latin America $(1021 \mathrm{~km}, 6.2 \%)$. Africa and Oceania have only two (Algiers and Cairo) and one (Sydney) cities, respectively, with subway systems to date. A total of $4891 \mathrm{~km}$ subway networks was constructed after 2010 in China, accounting for $29.8 \%$ of the current global total. This implies the fast urbanization and latedevelopment advantages of China provoked by its infrastructure upgrading investment after the 2008 summer Olympics and global financial crisis (Shi and Huang, 2014).

Although subway growth patterns vary across regions, subway length is positively correlated with urban population and GDP. In other words, richer cities (in terms of GDP) and larger cities (in terms of population size) tend to have longer urban subway networks (see Fig. 2 and Fig. S2 to S4 in the Supplementary Information). Also, comparable urban subway length is identified in cities with larger built-up areas (between 400 and $2000 \mathrm{~km}^{2}$ ) in China and Europe. However, in Other Asia, North America, and Latin America, no correlations were found between subway length and built-up area, which is due mainly to the greatest extent of road networks (Miatto et al., 2017) but less developed subway systems in the U.S. and Canada, as well as the large differences of urban built-up area across countries in these regions (e.g., $5802 \mathrm{~km}^{2}$ in Brasilia (Brazil) and $223 \mathrm{~km}^{2}$ in Osaka (Japan)) (see in Fig. S5 in the Supplementary Information). Word region wise, the stronger correlation between subway length and GDP than the population and built-up area in North America suggests that subway systems were firstly constructed in richer cities (e.g., New York, Washington D.C, and Vancouver). Relatively weak correlations in other Asia reflect the socioeconomic disparities among countries in this region (e.g., Japan vs. India).

The four quadrants in Fig. 2a, b, and c divide world cities into four groups based on their subway and socioeconomic development status. By and large, most Chinese cities locate in the first quadrants in Fig. 2a, b, and c, indicating the rationality and urgency of subway development in China with increasing urban population and booming economy under a rapid urbanization 
(a)

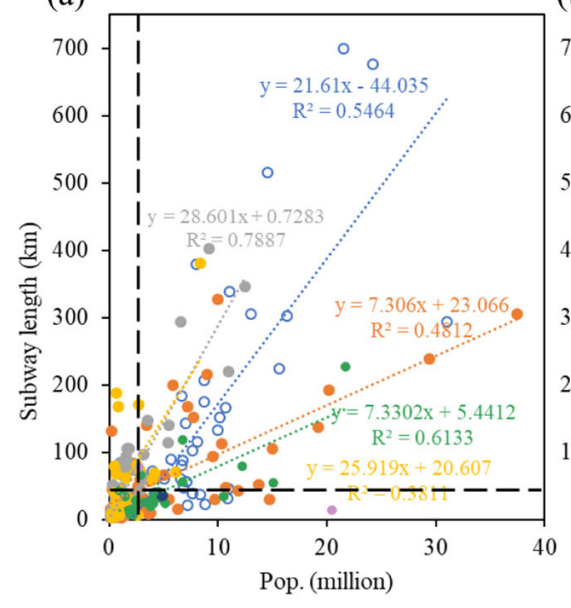

(b)

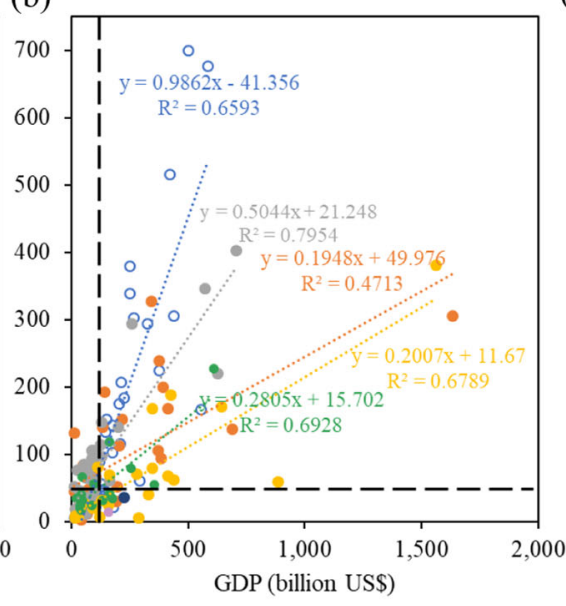

(c)

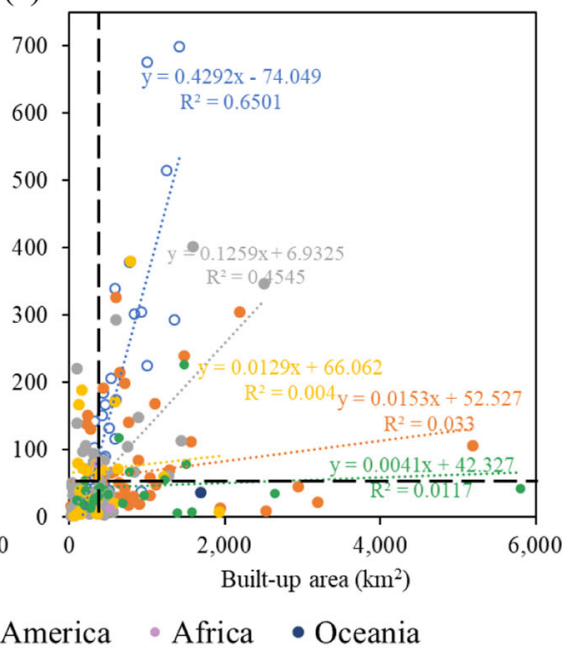

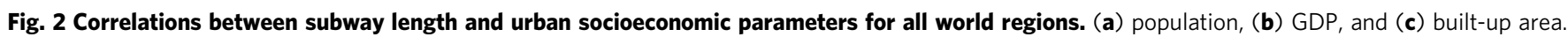
The results are presented in four quadrants based on median values (as dashed lines) of subway length, population, GDP, and built-up area for all cities. The regression trend lines of Africa and Oceania are not added because they only have a small number of cities with subways.

process (Li et al., 2020). In comparison, European and North American cities dominate the second quadrant in Fig. 2a and scattered widely in the first quadrant in Fig. $2 b$, signifying an urban expansion pattern with relatively low population, high GDP, and mature subway infrastructure. Cities in the third quadrants are mostly Latin American cities, which suggests a potential further increase in their total subway length as these cities continue to expand and develop economically. However, excessive subway construction in the past decade increased debt burdens of some local governments in China, so balancing the subway construction speed with needs will be essential for both financial and environmental sustainability. For example, in 2018, the Chinese government raised standards for the subway construction permit, from a threshold of 100 billion Chinese Yuan for GDP and 1 million for permanent urban residents to 300 billion Chinese Yuan and 3 million population (The State Council of the People's Republic of China, 2018).

Figure $3 \mathrm{a}, \mathrm{b}$ illustrate the annual ridership and crowdedness (measured by ridership per $\mathrm{km}$ subway length) compared with population density in the selected 25 cities with the world's busiest subway lines ( 5 cities for each world region). Both subway ridership and population density values in the selected Asian cities are higher, which reflects this region's efforts in the pedestrian-friendly design of subway networks and its significance for maximizing accessibility to transit (Jun et al., 2015). As it was found that a $10 \%$ increase in subway length will lead to a $6 \%$ increase in subway ridership (Gonzalez-Navarro and Turner, 2018), less crowded networks are found in mainland China compared with their congested counterparts such as Sao Paulo, Tokyo, and Hong Kong.

Figure 3c, d and Fig. S6 in the Supplementary Information present the growth patterns of per capita subway length with increasing GDP per capita and population density for the five selected Chinese megacities (Beijing, Shanghai, Guangzhou, Shenzhen, and Chengdu) in a context of world cities. The subway length and GDP, on a per capita level, have increased much more significantly (17-fold and 13-fold, respectively) than population (twofold) since 2000, reflecting the rapid urban infrastructure development (Bai et al., 2012; Peng et al., 2018) over the last two decades. However, a further increase of subway is still foreseeable in China, because: (i) China has higher population density, lower GDP, and shorter per capita subway length (averagely $27 \mathrm{~m}$ per thousand persons for the selected five Chinese cities, compared to $36 \mathrm{~m}$ and $120 \mathrm{~m}$ per thousand persons, respectively, for the selected European and North American cities) compared to industrialized countries; and (ii) The relative advantages of subways on energy efficiency, passenger convenience, and economic incentive, compared to other road transportation (e.g., private cars), have been particularly emphasized in China (Zhang et al., 2011).

\section{The material stocks in global urban subway systems}

The quantity, composition, growth and distribution of global subway material stocks. In total, $2460 \mathrm{Mt}$ (mean value, with a minimum of $2159 \mathrm{Mt}$ and a maximum of $2656 \mathrm{Mt}$ ) of construction materials are stocked in the subway networks of all the 219 world cities in 2020. This amount is around seven times larger than the global copper in-use stocks (Wiedenhofer et al., 2019) (See Fig. S7 and S8 in the Supplementary Information). Regarding the material composition, subway material stocks are dominated by nonmetallic mineral materials (93.7\%), represented by gravel $(1256 \mathrm{Mt})$, sand $(745 \mathrm{Mt})$, cement $(243 \mathrm{Mt})$, silica fume (33 Mt), and fly ash $(29 \mathrm{Mt})$. The material composition result allows for predicting the overall resource demand and the specific material requirement for building new subway systems in the future. For example, subway infrastructure construction requires significant amount of aggregates like gravel and sand. However, extensive mining of sand and gravel, as the largest consumed primary raw material ( $79 \%$ or 28.6 gigatons per year in 2010$)$ (Torres et al., 2017), are eroding river coastlines and placing burdens on habitat (United Nations Environment Program, 2019), as well as comprising the carbon uptake capacity of ecosystems (Torres et al., 2017). Preventing and reducing damages can thus be achieved by reducing sand and gravel consumption through better subway planning, simplified station design, and use of recycled and alternative materials for aggregates in subway construction. The metallic materials, despite of a very small share (5.1\%) of subway material stocks, in which steel $(125 \mathrm{Mt})$ and copper $(0.21 \mathrm{Mt})$ are the major two types (see Fig. S9 in the Supplementary Information), present a valuable source for future urban mining when these urban subway stocks are transformed from "probable" to "proved" in the future (McKelvey, 1972).

Temporal wise, the total amount of subway material stocks shows a significant growing trend in the past (See in Fig. 4a). 

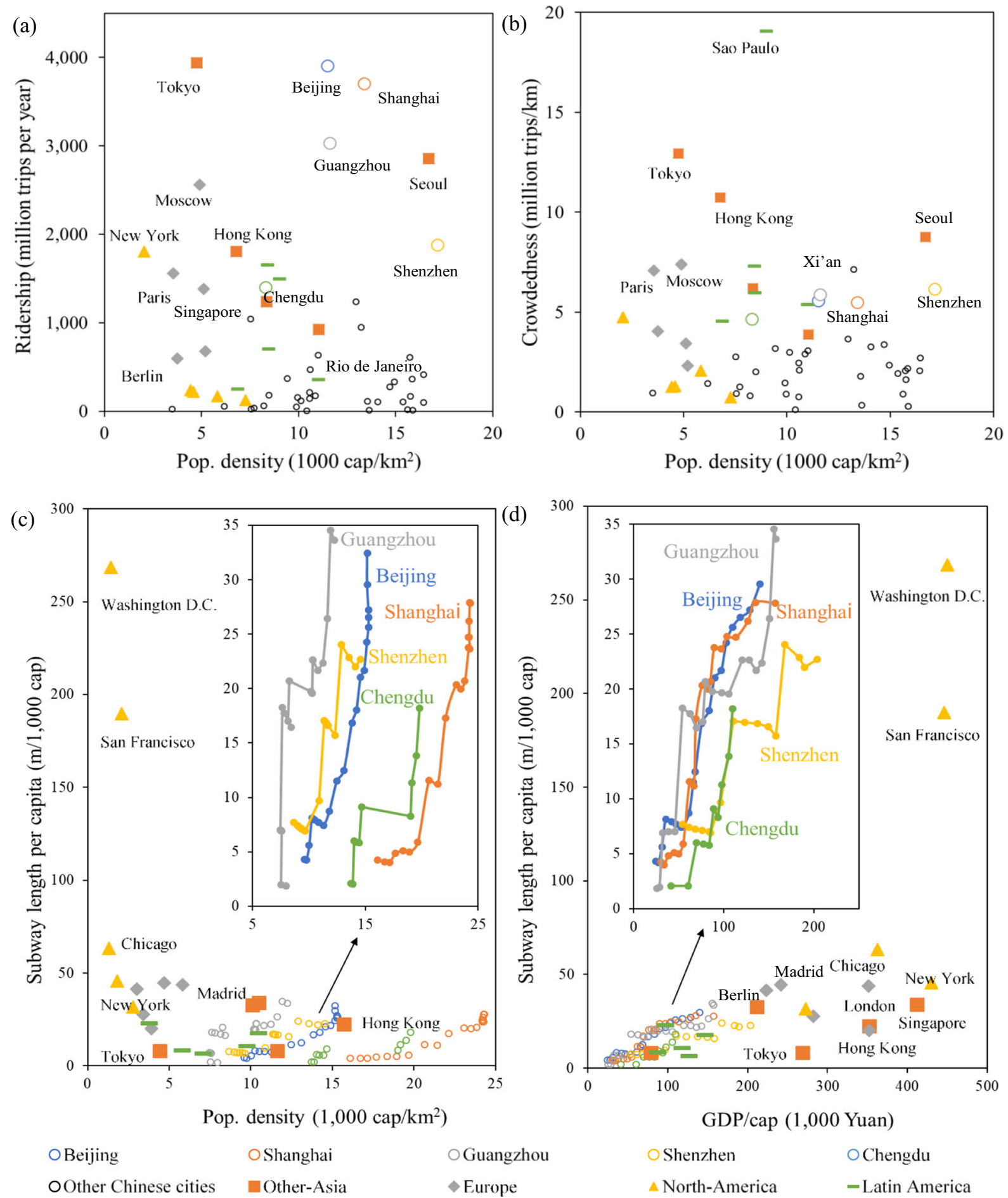

Fig. 3 Relationship of between subway ridership, crowdedness, and length with key socioeconomic factors in the selected 25 cities with the world's busiest subway lines. (a) Subway ridership and population density; (b) Subway crowdedness and population density; (c) Subway length per capita and population density; and (d) Subway length per capita and GDP per capita. The five selected Chinese cities are shown in the inner figures of (c) and (d), due to available historical data.

With the development of steam engines in the industrial revolution, London introduced the first subway line in the late nineteenth century. Since the early twentieth century, subway had become a feat of modern construction in North America and Europe, as well as the newest way to travel across the city, with an annual growth of $8 \mathrm{Mt}$ subway stock from the 1900s to $1920 \mathrm{~s}$. However, the stock accumulation speed slowed down to $3 \mathrm{Mt}$ per year from the 1930s to 1940s during the World War II. Since the 1970s, nevertheless, subway material stocks regained the momentum and increased dramatically. This stock expansion might be attributed to three major reasons: (1) the subway systems could provide cheap and efficient solutions to satisfy the increasing demand for commuting by public transportation in modern urban lives (Kang et al., 2020); (2) the innovations of tunnel boring machines and ventilation systems facilitated faster subway constructions (Liu et al., 2013; Agrawal et al., 2019); and 

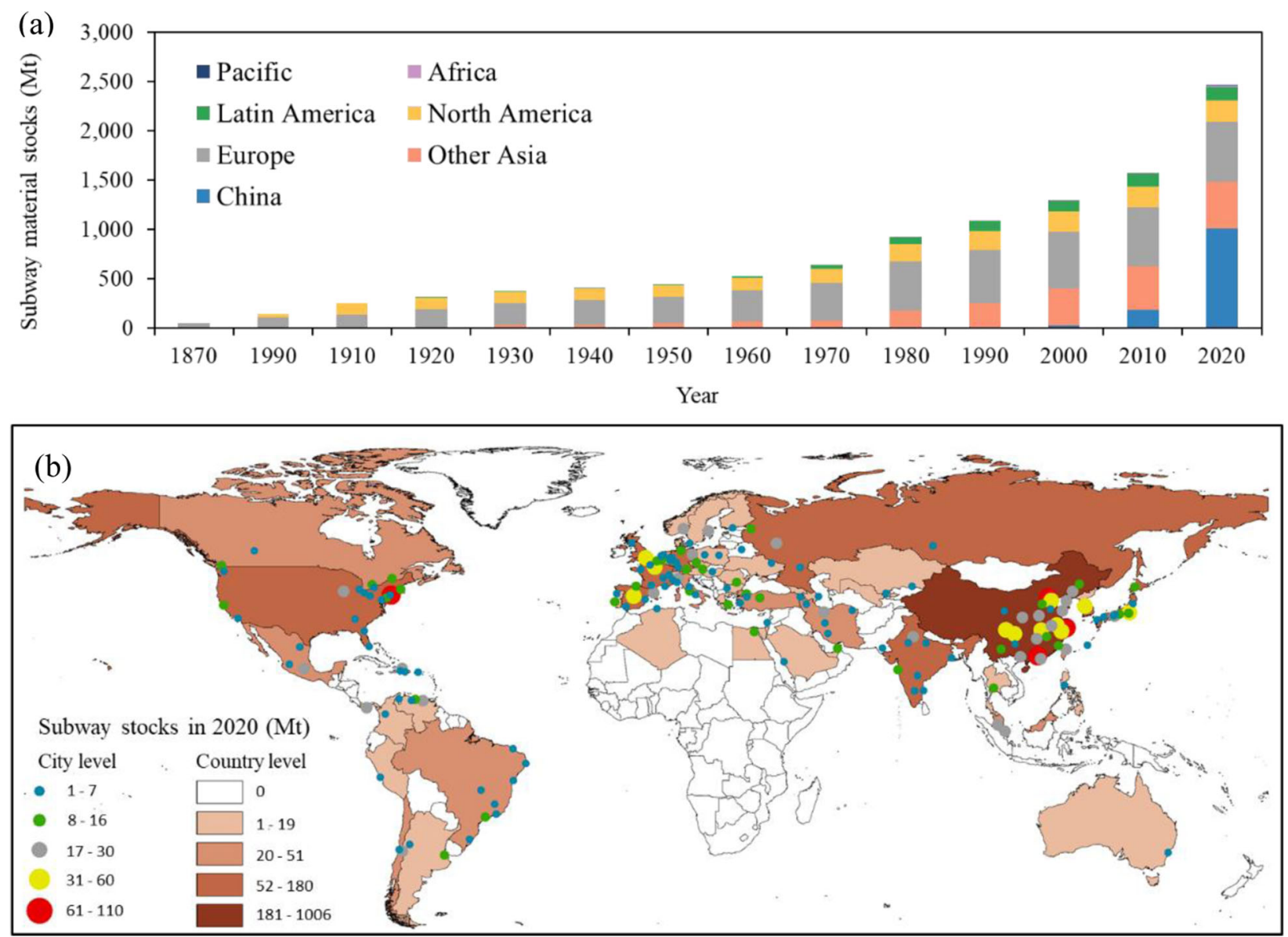

Fig. 4 The temporal and spatial patterns of global subway material stocks. (a) The temporal growth patterns by world region, 1870-2020; and (b) the spatial distribution at city and country levels by July 2020 .

(3) the accelerating modernization and urbanization in developing countries in the recent decades, especially for China.

Since the 1990s, the increasing Chinese investment in its urban infrastructure gathered $975 \mathrm{Mt}$ (or $49 \mathrm{Mt} / \mathrm{a}$ ) subway stocks from 2000 , leading to $47 \%$ of the global subway material stocks accumulated in the past two decades in China. The year 2019 has witnessed a record high stock accumulation in which $153 \mathrm{Mt}$ construction materials are consumed in Chinese newly built subway system (see Fig. S10 in the Supplementary Information). Consequently, subway in Chinese cities accumulated $1006 \mathrm{Mt}$ of construction materials and contributed to $41 \%$ of global subway material stocks by 2020 . This amount is around six times higher than the second largest subway stock county (178 Mt in the United States) and approximately the same as the total construction materials in all Swiss residential buildings (1075 Mt in 2015) (Heeren and Hellweg, 2019). Moreover, the highest subway stock cities (in total 17 cities, as marked in yellow and red in Fig. 4b) are mostly distributed in China, with only a few exceptions such as New York, Paris, Seoul, Madrid, and Tokyo. Therefore, identifying the characteristics of subway materials stocks in China is imperative for forecasting future resource demand of other Chinese cities and cities in other developing countries to reach the same subway service level of the present Chinese and world megacities' levels, as well as for mitigating the associated environmental impacts for global GHG emission reduction.

The spatial characteristics of subway material stocks in China. The significance of Chinese cities in global subway stocks growth identified above indicates a necessity to better characterize the spatial distribution of subway material stocks within China. Fig. 5a and Fig. S11 show that subway material stocks range widely between 3.95 Mt and 110.27 Mt across cities in China. With the most complex subway networks, material stocks in Shanghai (110.27 Mt), Beijing (104.85 Mt), and Guangzhou (71.87 Mt) are among the top three. Although Beijing has the longest subway lines, its total subway material stocks are lower than that of Shanghai (which has the most stations), signifying the considerable construction materials stocked in subway stations. Furthermore, the per capita subway stocks in Nanjing $(5.65 \mathrm{t} / \mathrm{cap})$ and Wuhan $(5.43 \mathrm{t} / \mathrm{cap})$ are higher than other cities, due mainly to their smaller population size.

Regionally, the majority of subway material stocks $(78 \%$ of total) are distributed in China's five major urban agglomerations: the Yangtze River Delta with eight cities accumulate $293 \mathrm{Mt}$ materials (29\% of total), followed by Jing-Jin-Ji Metropolitan Region (152 Mt), Pearl River Delta (137 Mt), Middle Yangtze Plain (102 Mt), and Cheng-Yu Metropolitan Region (100 Mt). In addition, the $\mathrm{Hu}$ Line that divides China into two halves and the southeast half accounted for $43 \%$ of the land but $96 \%$ of the population (Qi et al., 2016), also separated the subway material stocks with $98.4 \%$ in the southeast and $1.6 \%$ in the northwest. Only three cities, namely Urumqi (5.5 Mt), Lanzhou (5.2 Mt), and Hohhot (5.12 Mt), in the northwest of Hu-line operated their first subway lines in 2019. Under the economic development policies for central and western China, the government should further address this unbalanced infrastructure growth in agreement with socioeconomics between east and west China 

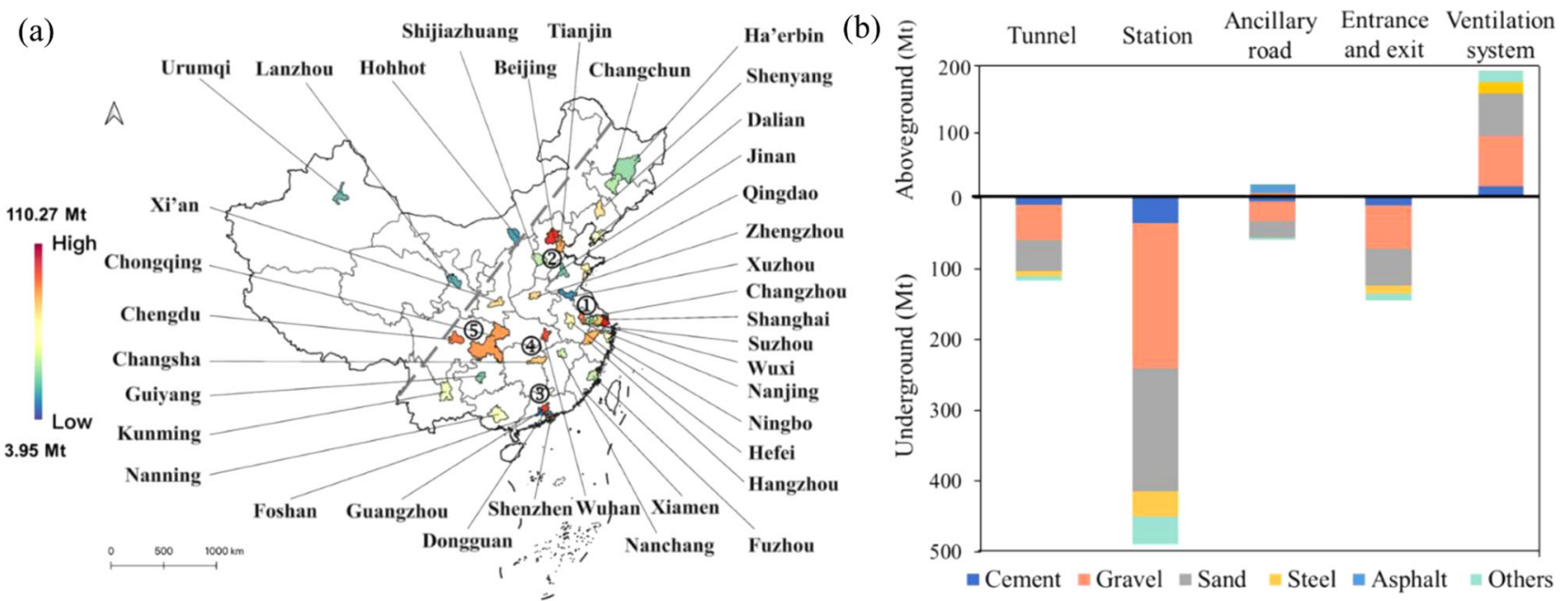

Fig. 5 The spatial characteristics of China's subway material stocks. (a) Subway material stocks, geographical locations, and spatial boundaries of the 37 Chinese cities; and (b) The stock quantity and vertical distribution (above- and underground) by construction material and by component. Note: The five major urban agglomerations in a are (1) Yangtze River Delta, (2) Jing-Jin-Ji Metropolitan Region, (3) Pearl River Delta, (4) Middle Yangtze Plain, and (5) Cheng-Yu Metropolitan Region; the gray dashed line is the Hu Line.

(Cao et al., 2014) (See in Fig. 5a). Taking a long-time perspective, however, the level of subway material stocks is approaching saturation gradually in the eastern regions, which implies cities in central and western China deserve future attention.

Components investigation shows differences in Chinese subway material stocks quantity, composition, and above- and underground distributions (Fig. 5b). Stations contribute almost half of the total material stocks (491 Mt), followed by ventilation system (179 Mt) and entrance and exit (145 Mt), implying the importance of comprehensive subway material stocks estimation instead of merely focusing on tunnels. Material distributions in components depict that all copper and half steel are identified in stations, and $99 \%$ asphalt is in ancillary roads. Except for the ventilation systems and ancillary roads' surface, most materials are accumulated underground ( $812 \mathrm{Mt}$, or $80.7 \%$ of total), highlighting the challenges of future urban mining and the importance of pre-demolition resource prospecting (Blasenbauer et al., 2020). The considerable underground subway stocks also indicate the huge mass of subway-related excavated soil and rock generated and dumped in construction periods, and sorting and recycling these resources will be beneficial and essential (Zhang et al., 2020).

Fig. 6 and Fig. S12 to S48 in the SI present the urban subway resource cadaster developed in a high resolution $(500 \times 500 \mathrm{~m})$, which could facilitate the secondary resource prospecting based on the distribution of material types, quantities and locations of subway stocks over a city. The cases of Shanghai, Suzhou, and Lanzhou (Fig. 6a) exemplify the material stocks spatial characteristics, distributions, and growth patterns (from linear distribution in Lanzhou to network characteristics in Shanghai) among Chinese cities (see group classification for all the 37 cities in Table S57 in the Supplementary Information). Station related construction (including station, ventilation system, entrance and exit, and ancillary road) accumulated considerable materials. However, the proportion of station stocks in total subway material stocks decreases when subways expand from linear (e.g., $51 \%$ in Hohhot with one subway line) to networks (e.g., $47 \%$ in Guangzhou with 14 subway lines) because stations are shared among more lines. The identified patterns behind spatial materials growth and the importance of location selection for transit subway stations could help to establish different subway development plans for other cities.
The vertical distribution of subway material stocks for the case of Shanghai in Fig. 6b shows the underground subway material stocks is higher in station locations and lower along tunnels (blue, green, and yellow colors in Fig. 6b). Above-ground stocks with less material stocks volume distribute in the ventilation system and ancillary road. Such a subway secondary resource cadaster also presents the material composition in each grid. Fig. $6 c$ shows an example for the largest subway material stocks grid in China (found around Shanghai Century Avenue subway station), which weighs $973 \mathrm{kt}$. This weight is dominated by gravel ( $417 \mathrm{kt})$ and sand (352 kt), with $78.9 \%$ distributed in underground. Understanding the vertical stock distributions at grid level across Chinese cities will facilitate explicit waste management strategies in the future.

Different from the relatively significant correlation between population density and urban built-environment stocks on a gridded level in Shanghai (Han et al., 2018) and Beijing (Mao et al., 2020), gridded subway material stocks arbitrarily distributes in five categories (with 0 to 4 stations in each grid) and no correlations are observed with gridded population density (see in Fig. S49 in the Supplementary Information). This can be explained by the fact that: (i) subway networks offer commuting services to all city residents; and (ii) built-environment stocks in the denser area reflect more working and living spaces they provided to people.

It should be pointed out that, when data allow, such analysis for China, as the world's largest subway stock contributor, could be extended to other countries and cities as well (which is currently not possible due to data gaps on geolocalized subway information including polyline data for tunnels and polygon data for stations for non-Chinese cities). In general, identifying these spatiotemporal characteristics of subway materials stocks development is imperative for benchmarking future resource demand of other developing countries and cities as they continue to urbanize, as well as for informing sustainable subway planning, prospecting urban mining and waste management opportunities and challenges, and mitigating the associated environmental impacts for global GHG emission reduction.

The characteristics and mitigation of embodied emissions in global subway systems. In 2020, the construction materials in global subway systems equal to $560 \mathrm{Mt}$ of embodied GHG emissions (mean value, with a minimum of $494 \mathrm{Mt}$ and a 


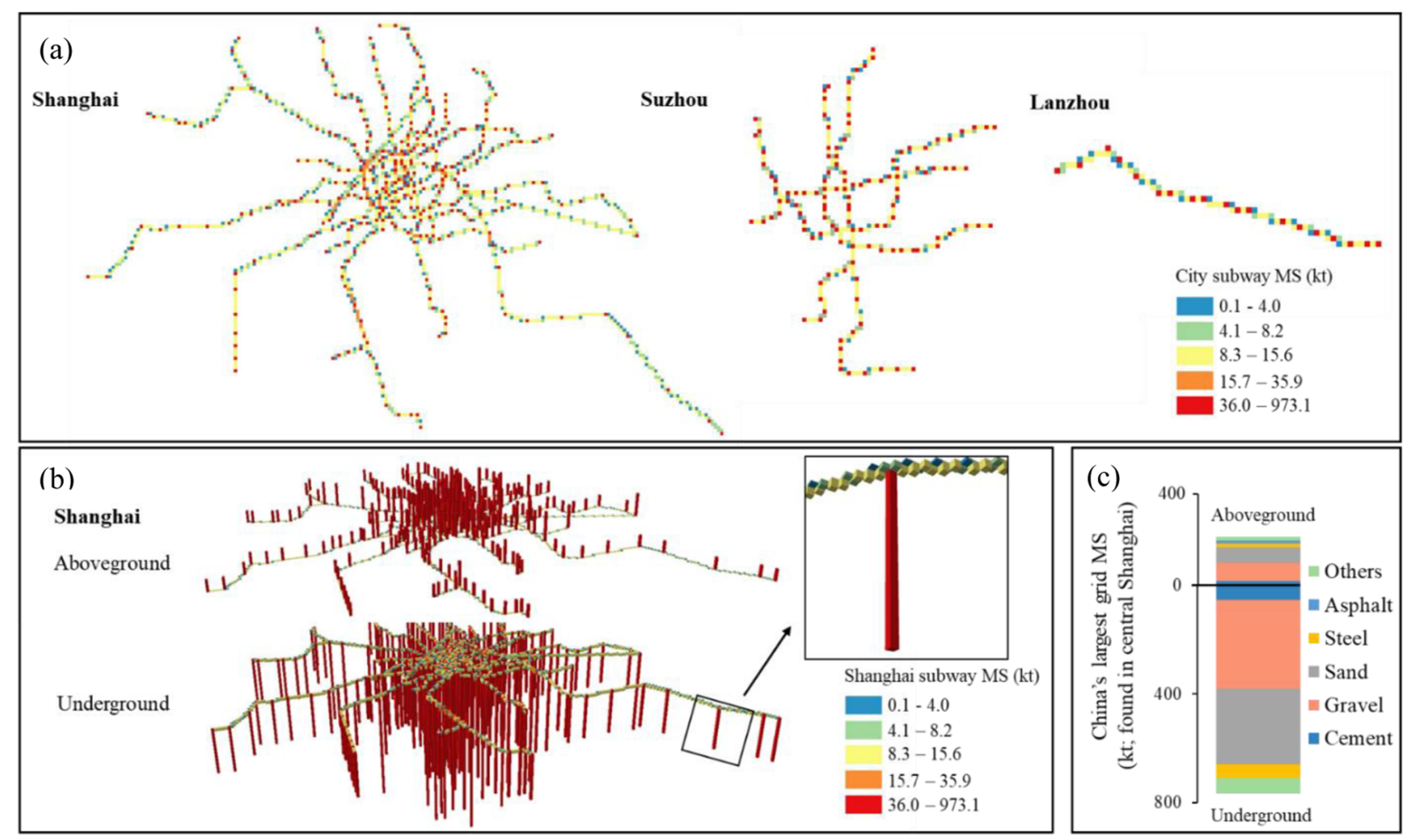

Fig. 6 Spatial distribution of subway material stocks, as of July 2020, for case Chinese cities. (a) For Shanghai, Suzhou, and Lanzhou; (b) For above- and underground in Shanghai; and (c) For vertical distribution of the largest subway stock grid in China (found in central Shanghai). Note the orange and red colors, respectively, represent one and two to four stations in (a) and (b).

maximum of $604 \mathrm{Mt}$ ), in which steel contributes the most (333 $\mathrm{Mt}, 59 \%)$, followed by cement (205 Mt, 37\%) and mortar (12 Mt, $2.2 \%$ ). This amount of embodied GHG emissions is about $37 \%$ of the global cement production emissions in 2019 (1.5 gigatons) (Andrew, 2019). While it is true that subways contribute much less to the total operational emissions of the transportation sector (3\% of the total (Liu et al., 2018); see details in Fig. S51 in the Supplementary Information), especially when compared to passenger vehicles ( $36 \%$ of the total), the embodied emissions of construction materials in the future subway development should not be overlooked. By comparing the operational carbon emissions of subway transport (including subway driving traction and station power and lighting), the embodied emissions equal to about 23 years of operational emissions, which need to be addressed for an even more sustainable and low-carbon transportation transition (Dong et al., 2018).

Significantly, the embodied emissions in China's subway networks are calculated as $261 \mathrm{Mt}$, accounting for almost half (47\%) of the global total. Along with the subway stock growth, Fig. 52a presents a dramatic emission increase in China since 2011, with an annual increase of $19 \mathrm{Mt} \mathrm{CO}_{2} \mathrm{e}$. Construction of subway station (50\%), ventilation system (22\%), and entrance and exit $(15 \%)$ create staggering climate impacts in China due to the use of energy-intensive materials, particularly for steel (182 Mt or $70 \%$ ) and cement (71 Mt or 22\%) (see in Fig. S52b in the Supplementary Information).

Globally, Shanghai contributes with the largest share of embodied $\mathrm{CO}_{2}$ emissions (28.6 Mt) among all 219 world cities with subways, followed by Beijing (27.2 Mt), Guangzhou (18.6 $\mathrm{Mt})$, and Wuhan (15.7 Mt). New York (14.8 Mt) is the only outside China city among the top 10 cities regarding embodied emissions. Moreover, the embodied GHG emissions correlate well with the length of subway networks $\left(R^{2}=0.906\right)$ among global cities (see in Fig. S53 in the Supplementary Information).
However, cities with denser subway stations show higher embodied emissions because of the large consumption of energy-intensive materials (i.e., cement and steel) in station construction. For example, London $(402 \mathrm{~km})$ is operating longer subway line than New York $(380 \mathrm{~km})$, but the embodied GHG emissions in New York $(14.8 \mathrm{Mt})$ is larger than that in London (9.9 Mt) due to denser subway stations (424 in New York vs. 270 in London).

The wave of global subway development associated with the consumption of steel, cement, and other construction materials will cause an increasing amount of GHG emissions. Our findings in this study, correspondingly, help identify a few key socioeconomic, technological, and planning strategies to support relevant industry stakeholders and policy makers for mitigating such emissions. Firstly, as for the materials with high GHG emission burdens such as steel and cement, reducing the fossil fuels by renewable energy sources during manufacturing is presumably one of the most effective approaches (Davis et al., 2018). For example, introducing energy-saving technologies for steel plants (Yu et al., 2015) and cement kilns (Gao et al., 2017) will significantly decrease the process emissions. Improving the recycling rate of steel scrap could also meet the continuing steel demand in subway construction and mitigate climate change (Pauliuk et al., 2013). Secondly, our results identified that station construction contributes to $72 \%$ of total embodied emissions in the global subway systems. Thus, better architectural designs of subway stations through the leaner structures and less materialintensive architecture will significantly mitigate the impacts in stations construction (Saxe et al., 2017). Thirdly, timber and other traditional bio-based materials (e.g., bamboo, straw, and hemp) could store a considerable carbon with a relatively small ratio of emissions to the material mass, while the most-widely used subway materilas hardly store any carbons (Churkina et al., 2020). Timber subway stations have been proved successful and 
sustainable at Norwest Station in Sydney (Sydney Metro, 2019). Partial substitution of concrete and steel with bio-based materials in station construction should be considered. Last but not least, as demonstrated in the case of spatial analysis of Chinese subway stocks, optimized spatial planning for the distribution of both subway lines and stations will minimize material and energy consumptions through the entire lifespan including subway construction, operation, and waste management stages.

Limitations and uncertainties. The subway material stock results presented above unavoidably bear limitations and uncertainties. For example, our sensitivity analysis of stock estimation shows that the year $2019(42.1 \%)$ and $2010(9.8 \%)$ contribute most to the uncertainty of subway material stocks in China, while the MCIs of gravel $(76.8 \%)$ and sand $(17.8 \%)$ consumed in subway station influence most of the non-Chinese subway material stocks (see in Fig. S50). Further, due to the untraceable subway construction history in the 182 non-Chinese cities, we assumed that all of their subway material stocks by 2020 were accumulated in the first year of operation, which would result in an overestimate of historical subway stocks for these cities. Moreover, a small share of subway tunnels is constructed above ground according to local geological conditions, but this is not considered (so all tunnel material stocks are assumed underground) due to data gaps. The estimation of embodied emissions in global subway systems can be thus affected by these uncertainties in stock quantification. Also, the waste generation from subway construction activities or maintenance works is not included either, which should be further addressed by linking subway stocks with flows (construction, maintenance, and demolition) in a prospective model. Nevertheless, our results provide a good overview on the quantity, quality, growth patterns, and spatial distributions of global subway material stocks, which could be used to inform decision-makers in waste management about where materials are to be replaced and/or recycled in the future and enable sustainable subway planning with circular economy strategies (Schiller et al., 2017).

\section{Data availability}

The supported data sources are publicly available, and their citations are mentioned in references of this paper and the Supplementary Information file. Additional information regarding the study can be obtained from the corresponding author upon a reasonable request.

Received: 1 August 2020; Accepted: 23 February 2021; Published online: 19 March 2021

\section{References}

Agrawal AK, Murthy VMSR, Chattopadhyaya S (2019) Investigations into reliability, maintainability and availability of tunnel boring machine operating in mixed ground condition using Markov chains. Eng Fail Anal 105:477-489. https://doi.org/10.1016/j.engfailanal.2019.07.013

Andrew, R. M. (2019). Global CO2 emissions from cement production, 1928-2018. Earth Syst Sci Data. https://doi.org/10.5194/essd-11-1675-2019.

AutoNavi Company (2020) Subway Infrastructures Footprint Data [WWW Document]. URL https://map.amap.com/subway/index.html?\&1100

Bai X, Chen J, Shi P (2012) Landscape urbanization and economic growth in China: positive feedbacks and sustainability dilemmas. Environ Sci Technol 46:132-139. https://doi.org/10.1021/es202329f

Beijing Mass Transit Railway Operation Corporation Limited (2020) Beijing Subway Information [WWW Document]. URL https://www.bjsubway.com/ en/ (Accessed 27 Aug 19)

Beijing Municipal Bureau of Statistics (2020) Beijing Statistical Yearbook 2019 [WWW Document]. China Stat. Press. URL http://nj.tjj.beijing.gov.cn/nj/ main/2019-tjnj/zk/indexch.htm
Blasenbauer D, Bogush A, Carvalho TT, Cleall P, Cormino C, Guglietta D, Fellner J, Fernández-Alonso M, Heuss-Aßbichler S, Huber F (2020) Knowledge base to facilitate anthropogenic resource assessment, in: knowledge base to facilitate anthropogenic resource assessment. Technische Universität Wien Research Center for Waste and Resource Management

Brookings Institute (2018) Global Metro Monitor 2018 [WWW Document]. URL https://www.brookings.edu/wp-content/uploads/2018/06/BrookingsMetro_Global-Metro-Monitor-2018.pdf

Cao S, Lv Y, Zheng H, Wang X (2014) Challenges facing China's unbalanced urbanization strategy Land Use Policy 39:412-415

Chenyihsu Y, Whalley A (2012) Green infrastructure: the effects of urban rail transit on air quality. Am Econ J Econ Policy 4:58-97. https://doi.org/ 10.1257/pol.4.1.58

Churkina G, Organschi A, Reyer CPO, Ruff A, Vinke K, Liu Z, Reck BK, Graedel TE, Schellnhuber HJ (2020) Buildings as a global carbon sink. Nat. Sustain 3:269-276. https://doi.org/10.1038/s41893-019-0462-4

CLCD Database (2015) Chinese core life cycle database version 0.8. Available at eBalance 4.7 Software

Davis SJ, Lewis NS, Shaner M, Aggarwal S, Arent D, Azevedo IL, Benson SM, Bradley T, Brouwer J, Chiang YM, Clack CTM, Cohen A, Doig S, Edmonds J, Fennell P, Field CB, Hannegan B, Hodge BM, Hoffert MI, Ingersoll E, Jaramillo P, Lackner KS, Mach KJ, Mastrandrea M, Ogden J, Peterson PF, Sanchez DL, Sperling D, Stagner J, Trancik JE, Yang CJ, Caldeira K (2018). Net-zero emissions energy systems. Science (80-.). https://doi.org/10.1126/ science.aas 9793

Dong D, Duan H, Mao R, Song Q, Zuo J, Zhu J, Wang G, Hu M, Dong B, Liu G (2018) Resources, conservation \& recycling towards a low carbon transition of urban public transport in megacities: a case study of Shenzhen, China. Resour Conserv Recycl 134:149-155. https://doi.org/10.1016/j.resconrec.2018.03.011

Faivre d'Arcier B (2014) Measuring the performance of urban public transport in relation to public policy objectives. Res Transp Econ 48:67-76. https://doi. org/10.1016/j.retrec.2014.09.033

Gao T, Shen L, Shen M, Liu L, Chen F, Gao L (2017) Evolution and projection of CO2 emissions for China's cement industry from 1980 to 2020 . Renew Sustain Energy Rev 74:522-537. https://doi.org/10.1016/j. rser.2017.02.006

Gassner A, Lederer J, Fellner J (2020) Material stock development of the transport sector in the city of Vienna. J Ind Ecol 1-15. https://doi.org/10.1111/ jiec. 13024

Gonzalez-Navarro M, Turner MA (2018) Subways and urban growth: evidence from earth. J Urban Econ 108:85-106. https://doi.org/10.1016/j.jue.2018.09.002

Greater London Authority (GLA) (2014) Global City Population Estimates [WWW Document]. London Datastore. URL https://data.london.gov.uk/ dataset/global-city-population-estimates

Guo Z, Shi H, Zhang P, Chi Y, Feng A (2017) Material metabolism and lifecycle impact assessment towards sustainable resource management: a case study of the highway infrastructural system in Shandong Peninsula, China. J Clean Prod 153:195-208. https://doi.org/10.1016/j.jclepro.2017.03.194

Han J, Chen W-Q, Zhang L, Liu G (2018) Uncovering the spatiotemporal dynamics of urban infrastructure development: a high spatial resolution material stock and flow analysis. Environ Sci Technol 52:12122-12132. https://doi.org/10.1021/acs.est.8b03111

Heeren N, Hellweg S (2019) Tracking construction material over space and time: prospective and Geo-referenced modeling of building stocks and construction material flows. J Ind Ecol 23:253-267. https://doi.org/10.1111/jiec.12739

Jun MJ, Choi K, Jeong JE, Kwon KH, Kim HJ (2015) Land use characteristics of subway catchment areas and their influence on subway ridership in Seoul. J Transp Geogr 48:30-40. https://doi.org/10.1016/j.jtrangeo.2015.08.002

Kang L, Sun H, Wu J, Gao Z (2020) Last train station-skipping, transfer-accessible and energy-efficient scheduling in subway networks. Energy 206:118127. https://doi.org/10.1016/j.energy.2020.118127

Kennedy CA (2002) A comparison of the sustainability of public and private transportation systems: study of the greater Toronto Area. Transportation (Amst) 29:459-493. https://doi.org/10.1023/A:1016302913909

Lanau M, Liu G, Kral U, Wiedenhofer D, Keijzer E, Yu C, Ehlert C (2019) Taking stock of built environment stock studies: progress and prospects. Environ Sci Technol 53:8499-8515. https://doi.org/10.1021/acs.est.8b06652

Lederer J, Kleemann F, Ossberger M, Rechberger H, Fellner J (2016a) Prospecting and exploring anthropogenic resource deposits: the case study of Vienna's subway network. J Ind Ecol 20:1320-1333. https://doi.org/ $10.1111 /$ jiec. 12395

Lederer J, Ott C, Brunner PH, Ossberger M (2016b) The life cycle energy demand and greenhouse gas emissions of high-capacity urban transport systems: a case study from Vienna's subway line U2. Int J Sustain Transp 10:120-130. https://doi.org/10.1080/15568318.2013.869704

Li B, Gao S, Liang Y, Kang Y, Prestby T, Gao Y, Xiao R (2020) Estimation of regional economic development indicator from transportation network analytics. Sci Rep 10:1-15. https://doi.org/10.1038/s41598-020-59505-2 
Li S, Liu Y, Purevjav AO, Yang L (2019) Does subway expansion improve air quality? J Environ Econ Manage 96:213-235. https://doi.org/10.1016/j. jeem.2019.05.005

Liu H, Lee S, Kim M, Shi H, Kim JT, Wasewar KL, Yoo C (2013) Multi-objective optimization of indoor air quality control and energy consumption minimization in a subway ventilation system. Energy Build 66:553-561. https:// doi.org/10.1016/j.enbuild.2013.07.066

Liu L, Wang K, Wang S, Zhang R, Tang X (2018) Assessing energy consumption, $\mathrm{CO} 2$ and pollutant emissions and health benefits from China's transport sector through 2050. Energy Policy 116:382-396. https://doi.org/10.1016/j. enpol.2018.02.019

Mao R, Bao Y, Huang Z, Liu Q, Liu G (2020) High-resolution mapping of the urban built environment stocks in Beijing. Environ Sci Technol 54:5345-5355. https://doi.org/10.1021/acs.est.9b07229

May AD (2013) Urban transport and sustainability: the key challenges. Int J Sustain Transp 7:170-185

McKelvey VE (1972) Mineral resource estimates and public policy: better methods for estimating the magnitude of potential mineral resources are needed to provide the knowledge that should guide the design of many key public policies. Am Sci 60:32-40

Metropolitan Transportation Authority (MTA) (2019) Subway and bus ridership for 2019 [WWW Document]. URL https://new.mta.info/agency/new-yorkcity-transit/subway-bus-ridership-2019

Miatto A, Schandl H, Wiedenhofer D, Krausmann F, Tanikawa H (2017) Modeling material flows and stocks of the road network in the United States 1905-2015. Resour Conserv Recycl 127:168-178. https://doi.org/10.1016/j. resconrec.2017.08.024

Müller DB, Liu G, Løvik AN, Modaresi R, Pauliuk S, Steinhoff FS, Brattebø H (2013) Carbon emissions of infrastructure development. Environ Sci Technol 47:11739-11746. https://doi.org/10.1021/es402618m

Nasri A, Zhang L (2014) The analysis of transit-oriented development (TOD) in Washington, D.C. and Baltimore metropolitan areas. Transp Policy 32:172-179. https://doi.org/10.1016/j.tranpol.2013.12.009

Nguyen TC, Fishman T, Miatto A, Tanikawa H (2019) Estimating the material stock of roads: the Vietnamese Case Study. J Ind Ecol 23:663-673. https://doi. org/10.1111/jiec. 12773

Pauliuk S, Milford RL, Müller DB, Allwood JM (2013) The steel scrap age. Environ Sci Technol 47:3448-3454

Pauliuk S, Venkatesh G, Brattebø H, Müller DB (2014) Exploring urban mines: pipe length and material stocks in urban water and wastewater networks: Research Article. Urban Water J 11:274-283. https://doi.org/10.1080/ 1573062X.2013.795234

Peng T, Ou X, Yuan Z, Yan X, Zhang X (2018) Development and application of China provincial road transport energy demand and GHG emissions analysis model. Appl Energy 222:313-328. https://doi.org/10.1016/j.apenergy.2018.03.139

Prud'homme R, Koning M, Lenormand L, Fehr A (2012) Public transport congestion costs: the case of the Paris subway. Transp Policy 21:101-109

QGIS (2018) Qgis: a free and open source geographic information system. Version 3.8. 0, Computer software. QGIS

Qi W, Liu S, Zhao M, Liu Z (2016) China's different spatial patterns of population growth based on the "Hu Line". J Geogr Sci 26:1611-1625. https://doi.org/ 10.1007/s11442-016-1347-3

Renne JL (2016) Transit oriented development: making it happen. Routledge

Saxe S, Miller E, Guthrie P (2017) The net greenhouse gas impact of the Sheppard Subway Line. Transp Res Part D Transp Environ 51:261-275. https://doi.org/ 10.1016/j.trd.2017.01.007

Schiller G, Müller F, Ortlepp R (2017) Mapping the anthropogenic stock in Germany: metabolic evidence for a circular economy. Resour Conserv Recycl 123:93-107. https://doi.org/10.1016/j.resconrec.2016.08.007

Serradell J, Kennes J (2017) World Metro Database [WWW Document]. Metrobits. Org. URL http://mic-ro.com/metro/table.html

Shanghai Municipal Bureau of Statistics (2020) Shanghai Statistical Yearbook 2019 [WWW Document]. URL http://tji.sh.gov.cn/tjnj/20200427/ 4 aa08fba106d45fda6cb39817d961 c98.html

Shi H, Huang S (2014) How much infrastructure is too much? A new approach and evidence from China. World Dev 56:272-286. https://doi.org/10.1016/j. worlddev.2013.11.009

Sydney Metro (2019) Project: Sydney Metro Northwest

Thacker S, Adshead D, Fay M, Hallegatte S, Harvey M, Meller H, O’Regan N, Rozenberg J, Watkins G, Hall JW (2019) Infrastructure for sustainable development. Nat Sustain 2:324-331. https://doi.org/10.1038/s41893-0190256-8

The State Council of the People's Republic of China (2018) Better management of urban rail transit [WWW Document]. URL http://english.www.gov.cn/ policies/latest_releases/2018/07/13/content_281476220528090.htm

Torres A, Brandt J, Lear K, Liu J (2017) A looming tragedy of the sand commons. Science (80-.) 357:970-971. https://doi.org/10.1126/science.aao0503
U.S. Census Bureau (2020) City and town population totals: 2010-2019 [WWW Document]. URL https://www.census.gov/data/tables/time-series/demo/ popest/2010s-total-cities-and-towns.html

UITP (International Association of Public Transport), (2018). World Metro Figures 2018. UITP (International Association of Public Transport). p. 8

United Nations Environment Programme (2019) Sand and sustainability: finding new solutions for environmental governance of global sand resources. United Nations Environment Programme p. 35

Wang T, Zhou J, Yue Y, Yang J, Hashimoto S (2016) Weight under steel wheels: material stock and flow analysis of high-speed rail in China. J Ind Ecol 20:1349-1359. https://doi.org/10.1111/jiec.12383

Wann-Ming W (2019) Constructing urban dynamic transportation planning strategies for improving quality of life and urban sustainability under emerging growth management principles. Sustain Cities Soc 44:275-290. https://doi.org/10.1016/j.scs.2018.10.015

Wiedenhofer D, Fishman T, Lauk C, Haas W, Krausmann F (2019) Integrating material stock dynamics into economy-wide material flow accounting: concepts, modelling, and global application for 1900-2050. Ecol Econ 156:121-133. https://doi.org/10.1016/j.ecolecon.2018.09.010

WorldPop Mainland China dataset (2020) WorldPop Mainland China dataset for 2020. The WorldPop project

Wu W, Hong J (2017) Does public transit improvement affect commuting behavior in Beijing, China? A spatial multilevel approach. Transp Res Part D Transp Environ 52:471-479. https://doi.org/10.1016/j.trd.2016.08.032

Yang J, Chen S, Qin P, Lu F, Liu AA (2018) The effect of subway expansions on vehicle congestion: evidence from Beijing. J Enviro Econ Manage 88:114-133. https://doi.org/10.1016/j.jeem.2017.09.007

Yu B, Li X, Qiao Y, Shi L (2015) Low-carbon transition of iron and steel industry in China: carbon intensity, economic growth and policy intervention. J Environ Sci (China) 28:137-147. https://doi.org/10.1016/j.jes.2014.04.020

Zhang J, Xu X, Hong L, Wang S, Fei Q (2011) Networked analysis of the Shanghai subway network, in China. Phys A Stat Mech Appl 390:4562-4570. https:// doi.org/10.1016/j.physa.2011.06.022

Zhang N, Duan H, Sun P, Li J, Zuo J, Mao R, Liu G, Niu Y (2020) Characterizing the generation and environmental impacts of subway-related excavated soil and rock in China. J Clean Prod 248:119242. https://doi.org/10.1016/j. jclepro.2019.119242

Zhou J, Murphy E, Long Y (2019) Commuting efficiency gains: assessing different transport policies with new indicators. Int J Sustain Transp 13:710-721. https://doi.org/10.1080/15568318.2018.1510562

\section{Acknowledgements}

This work is funded by the National Natural Science Foundation of China (71991484, 71991480), China Scholarship Council (201708440214), and Shenzhen Science and Technology Plan (JCYJ20190808123013260)

\section{Competing interests}

The authors declare no competing interests.

\section{Additional information}

Supplementary information The online version contains supplementary material available at https://doi.org/10.1057/s41599-021-00757-2.

Correspondence and requests for materials should be addressed to G.L.

Reprints and permission information is available at http://www.nature.com/reprints

Publisher's note Springer Nature remains neutral with regard to jurisdictional claims in published maps and institutional affiliations

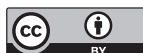

Open Access This article is licensed under a Creative Commons Attribution 4.0 International License, which permits use, sharing adaptation, distribution and reproduction in any medium or format, as long as you give appropriate credit to the original author(s) and the source, provide a link to the Creative Commons license, and indicate if changes were made. The images or other third party material in this article are included in the article's Creative Commons license, unless indicated otherwise in a credit line to the material. If material is not included in the article's Creative Commons license and your intended use is not permitted by statutory regulation or exceeds the permitted use, you will need to obtain permission directly from the copyright holder. To view a copy of this license, visit http://creativecommons.org/ licenses/by/4.0/

(c) The Author(s) 2021 